\title{
CONSTRUCTING A PROFESSIONAL IDENTITY: HOW YOUNG FEMALE MANAGERS USE ROLE MODELS
}

\author{
Val Singh, Susan Vinnicombe and Kim James \\ Centre for Developing Women Business Leaders \\ Cranfield School of Management, Cranfield University \\ Bedford MK43 OAL, UK \\ Tel: $+44(0)$ 1234-751122 \\ Fax: $+44(0)$ 1234-751806
}

Email: v.singh@cranfield.ac.uk; s.m.vinnicombe@cranfield.ac.uk; k.james@cranfield.ac.uk

This article has been accepted for publication in Women in Management Review, 2006

An earlier version of this article was presented at the $2^{\text {nd }}$ Gender, Work \& Organisation Conference, Keele, June 2003

\begin{abstract}
Role models are often identified as important for aspiring managers as they seek insights into how to develop themselves in their careers. There are, however, still few female role models at the top of companies. This project explores how young careerminded women use role models. It draws on previous research into how professionals experimented with their identity projections to become partners in US professional service firms. In-depth interviews with ten young professional women revealed that they actively draw on role models from different domains. In some cases, the role models were personally known to the individual women, whilst in other cases, they were personally unknown to them. The women revealed that they preferred to use the learning from external role models rather than focus on individual women from the top of their own professions. This research adds richness to our understanding of young female managers' use of role models, and contributes up-todate empirical evidence in a field which has been somewhat neglected in recent years.
\end{abstract}

Key words: Role Models, Women, Identity, Managers, Careers, Development

\section{Introduction}

Role models are often said to be key to the successful development of young aspiring managers. Role models, according to Shapiro, Haseltine \& Rowe (1978) are individuals whose behaviours, styles and attributes are emulated by others. Unlike mentors, who are always "close" in that they are personally known in an interactive relationship with the young individual, role models often are not acquainted with the role model user, nor do they give their permission to be used in this way. Hence, role models may be close or distant to the role model user.

In the Catalyst study of barriers for women's careers, the 500 European women reported the lack of female role models as the second biggest barrier (after stereotyping) to career success (Catalyst, 2003). There are few recent research reports into role modelling, the exception being Gibson (2003, 2004), who makes a strong case for reinvigorating the role model construct. The research literature has up to now focused on the related but more interactive phenomenon of mentoring rather than role modelling (Javidan, Bemmels, Devine and Dastmalchian, 1995). But little is known about how women choose or use role models. Role models may derive from a variety of domains, but again, there appears to be little research reported on role models and domains. The aim of this paper is to address that gap. We first consider the literature on role models, particularly for women aspiring to become managers. We pursue the idea of role model patterns as a framework for understanding role model development in a similar way to Higgins \& Kram's (2001) identification of mentoring sets. We then report findings from an empirical exploratory study in the UK of young women's role models, and their use of them. We conclude with suggestions for further research and consider implications for practice.

\section{Role Model Theory}

Social learning theory is useful in explaining how role modelling functions (Bandura, 1977). People observe the behaviour of others in given situations, and note the outcomes of those behaviours. Consequently, they use this knowledge to shape their own behaviour in similar contexts with 
expectations of similar outcomes. They are socialised into an appreciation of the values, abilities, expected behaviours and social knowledge essential for their new roles, particularly in organisational life (Louis, 1980). Through emulation of observed behaviours and career paths of their role models, the young managers and professionals enact their new roles (Schein, 1968; Hill, 1992).

So who are the role models drawn on for inspiration about careers? They may be existing leaders in a variety of fields, who display certain qualities, characteristics, attitudes and behaviours that are inspirational to others as models for the successful integration of self and the new career (Chung, 2000; Scarnati, 2002). Early role models are usually parents, modelling standards and providing a foundation for the development of their young offspring. Later role models are sought from a wider arena, and eventually, as careers become more important, from the corporate, entrepreneurial or professional worlds (Gibson, 2003). Often role models are selected because of the way in which they have overcome particular barriers seen as relevant by the users. The role models' behaviours are examined for guidance as to what is appropriate for particular organisations, for the level aspired to by the user, and relevance for the particular culture and context within which users are building their identity.

In a qualitative study of 22 investment bankers and 21 management consulting professionals, Gibson (2003) found career stage differences in the construction of role models, with early stage respondents drawing positive inferences from models who were close to them, to establish their self-concept, whilst middle and late stage interviewees drew on role models for guidance in refining and affirming their self-concept. Lockwood and Kunda (1997) reported that superstars are often selected as role models, when there is some relevance for the comparison, for example race, gender and personality, and grounds for belief that comparable success could be achieved. Whilst the superstars are often to be found in the same domain of excellence as the role model user, this is not an essential requirement. In the Lockwood and Kunda study, future teachers and accountants were inspired by leaders of the same gender as themselves in their professions. An important part of the value of role models is that they demonstrate the possibility of attainment for those similar to them. In this respect, they are symbols of possibility, offering inspiration, and removing uncertainty - the fact that role models have got there means that it is possible to do so, according to Chung (2000). He advocates affirmative action so that role models can play this role out more effectively through greater numbers.

\section{Building a Professional Identity}

As young people build their professional identities, they may draw on partial or total role models, and on positive or negative traits and behaviours as part of the learning process (Shapiro, Haseltine and Rowe, 1978; Lockwood, Jordan and Kunda, 2002; Gibson, 2003, 2004). Indeed, Shapiro et al. are not so positive about the usefulness of role models, especially in terms of helping women gain promotion, in contrast to mentors who are likely to be helpful.

They distinguished between total and composite role models. There was a danger for women who sought total role models, i.e. a single "idealised" person whose persona, behaviours and context incorporated all the characteristics identified by the user as essential for career success, as this was likely to be unrealistic. It is just as likely that a young role model user will draw on a number of individuals, selectively observing and copying what appears to be effective for career and life success. Bucher and Stelling (1977) found that students and young professionals exercised considerable judgement in the partial selection of role models. They too warned against females seeking only total role models and using only female role models for emulation. With both sexes in the role model set, young men and women could draw on a wider and more balanced range of behaviours to create a composite "ideal self" for their own aspiration as professionals.

Ibarra (1999) explored the development of 35 young professionals through the construction of provisional identities, as they progressed to more senior roles. The young consultants and investment bankers observed role models to identify potential identities, experimented with their provisional selves, and evaluated these experiments. The less successful tended to use total role models, whilst the more successful individuals constructed a composite template from several different role models. The process of identity formation in organisations described by Ashforth (1998) is relevant here, as individuals unfreeze their present identity, change it, and then refreeze it in the new mould when they have found the appropriate identity and behaviours to be effective in the new role.

In a qualitative study into key influences on directors' careers, Vinnicombe, Singh and Sturges (2000) found that women directors used role models to see what worked and what did not work, through their early interactions with board members. In these cases, the role models were more senior, close in terms of location, and personally known and observed by the female role model users in preparation for their director roles. Lockwood et al. (2002) found that individuals who were promotionoriented were more motivated by positive role models, whereas those who sought to prevent 
trouble were more motivated by negative role models who indicated ways of avoiding failure. But previous work on role models often has been undertaken in classroom conditions with students who may never have experienced organisational life (e.g. Lockwood and Kunda, 1997)). Hence more work is needed on samples who have worked in organisations, at a later stage of career development and investment. Gibson has renewed the interest in this area, mapping out the theoretical base for studies into role modelling, and suggesting more research into role model sets (Gibson, 2004).

\section{Lack of Female Role Models for Women}

As people seek role models as part of their career development, they often search for individuals with similar backgrounds to themselves. However, for minority individuals, including women, this can be difficult. Young women are often said to be disadvantaged by the lack of female role models at the top of organisations. Indeed, a Catalyst (2000) survey of current MBA students in the USA reported that $87 \%$ of women and $77 \%$ of men said that it was important or very important to feature more women business leaders as role models. However, in an earlier Canadian public sector study of 1579 senior managers, Javidan et al. (1995) found that female subordinates had no problems in accepting superiors of either sex as role models. In contrast, they found that male subordinates did not see their female superiors as role models. The critical factor for acceptance of a role model by both sexes was whether the subordinate perceived the superior to be successful or not, but the sex difference indicates persistence of the think manager, think male syndrome (Schein and Mueller, 1992).

There are very few women at board level in UK private sector companies, and only $4 \%$ of executive directors in the UK's top 100 companies are female (Singh and Vinnicombe, 2004). Women do not see themselves mirrored in the leadership, nor do others see women there, and this is likely to prolong the sex-role stereotyping of leadership as masculine.

\section{Changing Working Context}

Work-life balance has become a key issue for many of today's managers, particularly for women (Bailyn, Drago and Kochan, 2001). Hence, the way in which some high profile women manage their work/life balance has become of great interest in the media, and the few women who do apparently manage this well are role models for many younger female managers. As early as 1978, Shapiro et al. noted that selection of role models was encompassing patterns of how to manage work/life issues as well as 'on-the-job' behaviours. However, younger women may reject as role models the women at the top who do not have children. They are sometimes seen as having given up an essential part of their emotional and social capital to achieve success on masculine terms. Ely's (1994) study indicated that women in male-dominated professional firms were more likely to report that the women partners were not good role models because they were forming themselves in male moulds (e.g. working all hours, and laughing at sexist jokes), and were considered to be unlikely to facilitate the careers of more junior women. In contrast, women in sex-balanced firms reported women partners to be good role models (professional, stylish, accessible, and encouraging).

Women may also find role models outside the business world, perhaps in their social world, their family or community. Yet no academic studies were found about the sets and diversity of role models chosen by women aspiring to leadership, nor about the patterning of domains from which they are drawn. This study therefore explores the role models of young women between the ages of 25 and 37, at a career stage where they have invested in higher education and have some experience of working in organisations.

\section{A Developmental Network Perspective on Role Models}

Higgins and Kram (2001) identified a matrix of four different developmental networks of types of mentors. Developmental networks of mentors are defined as the set of people named by a protégé as taking an active interest and action to advance their career by providing developmental assistance. Taking a similar approach, the set of role models reported by an individual could be seen as a network providing both near and active as well as distant and passive career guidance. Young women use senior women and men as remote role models, as well as closer role models such as managers and mentors. As work-life balance is of increasing importance to women seeking management positions, we would expect to find that role model sets of a proportion of ambitious young women would include role models of work-life balance as well as high career attainment. This study explores the nature of the role model sets held by our sample of young women managers. In particular, we consider the number of role models, the sex of the role models, whether the role models are near or distant, and the learning acquired from the role models, as well as the number of domains from which the role models have been drawn. Some role models were in several domains (for example, a working mother role model might be in the female, family and business domains). 


\section{Methodology}

\section{Sample}

Young women attending a career seminar at a leading UK management school were invited to take part. Ten young professional women were interviewed, with ages between 25 and 37, average age 32. Six had postgraduate degrees and four had advanced professional qualifications. On average, they had eleven years of work experience including four years of project leadership, junior management or senior professional experience. Eight were British, and two were Japanese women currently based in the UK with their partners. None of the interviewees had children.

\section{Data Collection}

As this was an exploratory study, an interpretive approach was appropriate. Data gathering was through in-depth interviews, with questions sent in advance so that reflective responses could be made. Each interview lasted between 1-1/1/2 hours, and was taped and transcribed. Interview questions covered the following:

- Who are the role models, why have they been chosen, and the key characteristics of each person cited. Relevance of each role model for own career, and what has been learnt from the role model.

Interviewees were also asked to draw a network map of individual set of role models, with domains circled, to facilitate discussion of each role model and of the role model set.

Transcripts were imported into NVivo software for qualitative analysis. Patterns and commonalities were sought in the data, and themes identified and coded into a hierarchical tree structure with branches for role model dimensions, interviewees, learning, and set properties and dimensions (Lofland and Lofland, 1995). The theme of learning was broken down into personal characteristics, life management skills, task-related and people-related leadership skills.

\section{FINDINGS}

\section{The Role Model Users and their Career Histories}

A recurring theme in the interviews was the issue of confidence, despite these young professionals having had successful careers to date. Seven of the ten women indicated lack of confidence (worrying about what people thought them, worried about politics, putting themselves down, being naturally shy, concerned about how to influence people), and three of them had been advised to work on their lack of confidence for future development. Only one reported that a key strength was confidence. Every one of them said that they were highly motivated and hard working. Growing through challenges was an important feature of their careers, and some of them had high ambitions.

\section{The Role Models}

The young women had a variety of role models, some very well known, and in total, 50 role models were identified in their maps, 14 men and 36 women. From the political world, Margaret Thatcher was chosen; similarly, the two Japanese women chose a high profile Japanese career woman, Madame Ogata, the UN High Commissioner for Refugees. The young woman in PR had several news respondents as role models, identifying strongly how inspirational they had been in her development from an early age.
"Kate Adie - BBC war correspondent.
Because I wanted to be her. As a young child I wanted to be a war correspondent - I wanted the 'excitement' and the challenge of that role and I always admired her independence and her 'spirit'. As I grew up I realized how dangerous it was to be reporting on the war. Kate Adie demonstrated that women could be equals... anything a man can do..."

From the arts world, role models included a Japanese film star.
"Tomoko Yamaguchi, because she is of the same generation, with a good career, despite interrupting it when she got married, so it shows you can come back and begin again with ambition - that's why I admire her, and I am also breaking my career."

Marilyn Monroe was mentioned because she worked and got what she wanted through working with men, and the young TV chef Jamie Oliver was selected for his down-to-earth natural style and consideration for family relationships.

"The thing I really admire about him is that he doesn't appear to take life too seriously, there seems to be this balance between his passion around the food that he does, and there is always some fun aspect to it, like he scoots around London to get ingredients, all those involved sit down on a pier and eat it as a picnic. I just like that relaxed approach, have fun along the way and still come up with the goods." 
From the music world, Madonna and Kylie Minogue were chosen because they represented success in taking control of one's life, reinventing oneself, and knowing where they wanted to go, even after their initial careers had got stuck.

"From the age of 14 I admired Madonna. She's been exploited, and now as well as her music, she is a good businesswoman, and is respected by two generations. As a woman in her 40 s, she is still a sex icon, she is a working mother, she is confident, she has pushed down the barriers and didn't follow the rules. She has reinvented herself and succeeded in spite of the negative things that happen. I see this as empowering for women. She earned her success and took control of herself and the media."

From the fictional world, in the Harry Potter age, Professor Dumbledore was selected by one interviewee because he represented good leadership, he was fair, always knew what was going on and allowed others to grow. Another woman commented that her role model was a sort of Professor Dumbledore type.

"I like him because he is a really good decision-maker. In all the books, he steps in at just the right moment, so it is that balance. When someone comes in with a higher status, that's pretty critical, because if it's done in the right way, it allows others to grow around you, and share responsibility, so that they know their roles."

This choice links to the selection of $\mathrm{J} \mathrm{K}$ Rowling, the creator of Professor Dumbledore, as a role model by another of the interviewees. Buffy the vampire slayer was yet another fictional role model cited by two women, as inspiring confidence that women can take charge and overcome challenge, but only one included Buffy in her role model map.

Five women reported their mothers (and one grandmother) to be role models, whilst four gave their fathers and two mentioned sisters. A typical comment: "I look up to my mum. She was originally a secretary, worked her way up to a senior HR professional role, had two children, and had to work her way all the way up again." None gave brothers as role models, although one indicated that she might have included brothers, when we reviewed the role set with her and she realized it was all female. Five young women included former bosses, whilst three gave present bosses as role models.
Although $60 \%$ of the role models came from the business world, surprisingly few top businesswomen were included. Anita Roddick was given as the successful entrepreneur by a young woman whose ambition included aspirations to reach CEO level. She was also mentioned as inspirational by a young woman in PR, who hoped to start her own business. "Anita Roddick: Chosen because as a young child I remember seeing her on the news and it was almost unheard of to see a young woman pioneering her cause and being a successful businesswoman when many young girls thought they would be housewives not career women. She showed that anything was possible even as a woman. It was her entrepreneurial spirit and the fact that she believed in herself."

\section{The Role Model Domains}

The individual role model networks were characterised by domains with properties of gender, distance (distant or personally known), location (workplace, profession, family, business world, friends, etc) as a starting point for analysis. Table I provides a breakdown of the domains from which the role models were drawn.

Following Higgins and Kram's (2001) developmental network typology, we identified two dimensions to individuals' role model networks. These were:

- Whether an individual's role models came from a few or multiple domains (seven domains identified, a few being three or less, multiple being four or more);

- Whether an individual's role models were predominantly close (personally known to them) or distant (personally unknown to them, or fictional).

It is clear from Table II that there is a tendency to have personally known role models rather than distant, and to draw them from multiple rather than few domains. Eight of the ten women drew on role models from at least four domains, and the remaining two women drew from three domains. Seven of the women had a preference for close role models, and one had equal numbers of close and distant role models. Only two of the women showed a preference for distant role models. Whilst five women had mixed-sex role model sets, one woman had only male role models, whilst four others had only female role models. When reviewing the adequacy of the role model sets in meeting their developmental needs, several women noted the lack of senior women from their own organisation or their own business sector, and the lack of males or 
females to provide a male or female perspective respectively.

"As for shortcomings, they are nearly all in the same line of work and therefore offer a narrower viewpoint than if they represented different functions. They are all women - funny, didn't realize that until just now, interesting."

Table I: The Role Model Sets and Domains

\begin{tabular}{|c|c|c|c|c|c|c|c|c|c|c|}
\hline & SR & BJ & DK & UY & AY & $\mathrm{HM}$ & AS & WJ & SK & $\mathrm{FH}$ \\
\hline Number in set & 2 & 9 & 3 & 7 & 5 & 3 & 3 & 6 & 8 & 4 \\
\hline Family domain & $\mathrm{X}$ & $X X$ & $\mathrm{XX}$ & $\mathrm{XX}$ & $\mathrm{X}$ & & $\mathrm{X}$ & $\mathrm{XX}$ & $\mathrm{XX}$ & \\
\hline Friends domain & & $\mathrm{XX}$ & $\mathrm{X}$ & $\mathrm{XXX}$ & $\mathrm{XX}$ & & $\mathrm{XX}$ & $\mathrm{XX}$ & $\mathrm{XXX}$ & \\
\hline Business domain & $\mathrm{XX}$ & $\mathrm{XXXX}$ & $\mathrm{XX}$ & $\mathrm{XXXX}$ & $\mathrm{XXX}$ & $\mathrm{XXX}$ & $\mathrm{XX}$ & $\mathrm{XXX}$ & $\mathrm{XXX}$ & $\mathrm{XXXX}$ \\
\hline $\begin{array}{l}\text { Arts domain (Ballet, } \\
\text { Theatre, TV, Music, } \\
\text { Film, Literature, Art, } \\
\text { Craft) }\end{array}$ & & $\mathrm{XX}$ & & $\mathrm{X}$ & $x$ & $\mathrm{X}$ & & $\mathrm{X}$ & $X X X X$ & $\mathrm{XXXX}$ \\
\hline Fictitious domain & & $\mathrm{X}$ & & & & & & & $\mathrm{X}$ & \\
\hline Royal domain & & & & & $X$ & & & & & \\
\hline Political domain & & & & & & $x$ & & & & \\
\hline Female domain & & $X X X$ & $X X$ & $\begin{array}{l}X X X \\
X X X \\
\end{array}$ & $X X X X X$ & $X X X$ & $X X$ & $X X X$ & $\begin{array}{l}X X X X \\
X X X X\end{array}$ & $X X X X$ \\
\hline Male domain & $X X$ & $\begin{array}{l}X X X \\
X X X\end{array}$ & $\mathrm{X}$ & $X$ & & & $\bar{X}$ & $X X X$ & & \\
\hline $\begin{array}{l}\text { Number of } \\
\text { domains }\end{array}$ & 3 & 7 & 5 & 6 & 6 & 4 & 5 & 6 & 6 & 3 \\
\hline All Female Set & & & & & $X$ & $\mathrm{X}$ & & & $x$ & $\mathrm{X}$ \\
\hline All Male Set & $\mathrm{X}$ & & & & & & & & & \\
\hline Mixed-Sex Set & & $\mathrm{X}$ & $\mathrm{X}$ & $\mathrm{x}$ & & & $\mathrm{X}$ & $\mathrm{X}$ & & \\
\hline Close/Known & $X X$ & $\begin{array}{l}X X X X \\
X X X\end{array}$ & $\mathrm{XXX}$ & $X X X X X$ & $X X X$ & & $X X X$ & $X X X X X$ & $X X X X$ & \\
\hline Distant & & $\mathrm{XX}$ & & $\mathrm{XX}$ & $\mathrm{XX}$ & $X X X$ & & $\mathrm{X}$ & $X X X X$ & $\mathrm{XXXX}$ \\
\hline
\end{tabular}

Table II: Close/Distant and Few/Multiple Role Models

\begin{tabular}{|l|ll|l|l|}
\hline & \multicolumn{2}{|c|}{ Close Role Models } & Distant Role Models & \\
\hline $\begin{array}{l}\text { Role Model Set has Few } \\
\text { Domains }\end{array}$ & SR & FH 4 & 2 women \\
(from three domains) & & & & \\
\hline $\begin{array}{l}\text { Role Model Set has } \\
\text { Multiple Domains }\end{array}$ & BJ & 7 & BJ 2 & 8 women \\
(at least from 4 domains) & UY & 5 & SK 4 & \\
& SK & WJ & WJ 1 & \\
& AY & AY 2 & HM 3 & \\
& DK 3 & AS Distant Role Models & \\
\hline
\end{tabular}

\section{Learning from the Role Models}

The female interviewees were asked to comment not just on their role models but on the specific learning points from them. These fell into several categories. Many were about personal characteristics and style, and several stereotypically masculine traits emerged, such as control and determination. However, for several of them, there was a view that it was acceptable to be feminine in style, their role models had done it successfully and they wanted to emulate that femininity in their own careers.

"Learning from Madonna was that I can be carefree, feminine, 
attractive, and still be strong and go for things. She makes me admire her for her "I'm a force to be reckoned with" attitude. Be competitive, don't give respect just for the sake of it, don't be subservient. You don't have to conform, sexy dressing doesn't have to mean loose morals."

Another set of learning revolved around life skills, particularly that the quality of life is important. Some of these women had seen city "superwomen" and their demanding lives as something of a lesson for themselves. Whilst they admired the women at the top, they recognised that it came at a cost. For several interviewees, despite their professional careers, work/life balance was important to them, as was having a sense of fun at work.
"Jill Dando, the journalist and presenter. Because she was the 'local girl done good'. She flourished into a beautiful woman who was successful in her career but didn't find love till late in life - I identified with her in my 'singledom'. She sent out a message that even with such beauty and brains, love can sometimes evade you. More importantly, she showed that anyone could achieve their goals, and should not be held back by their background."

As role models are used to develop "ideal selves" for future career success, it is not surprising that much of the learning was associated with leadership. Some of this was related to managing tasks as leader, and came from watching much more senior people do their jobs well.

Importantly, there was a key kind of learning from watching their bosses managing and developing people. Several of the women said that they had learnt from observing negative as well as positive role models. For example, two had noticed the demotivating effects of leader moodiness, and took special efforts to be seen in positive mood. One learnt from her very successful father how to have respect for everyone, at whatever level, to deal with people calmly and to be genuinely interested in them. Two others commented on the way in which their male bosses had affirmed their competence, building their self-esteem and confidence. They had then tried out to replicate this with people junior to them, with successful results that pleased them enormously. One said:

"I undertook a task for my boss, and he sent a memo to his boss saying I had done it very well, which was super. And when I had to get the help of a junior person, I tried to be as supportive of everything she did, and I thought it would be nice for her to have that sort of affirmation, and so I repeated what my boss had done for me, but of course this was a much lower level. And she was so thrilled that I had done that. And to see that working down, that was a nice experience for me. It was that feeling of understanding how to deal with people that I learnt, it was a bit managerial, how to lead them and motivate them."

Another important theme emerging from the interviews was challenge, both in terms of their own need for challenge, and their understanding of how to give challenge to others in a supportive and developmental way. One respondent said that her director boss used to give her "a thimbleful of an idea, and tell me to go away and run with it". All he was interested in was that she delivered, but she felt that he was in a way testing her and developing her at the same time. She had to be quick on the uptake, be willing to admit what she didn't know and take the necessary action with very little solid information to go on. This learning was something that she now tried to provide for those in her team. Another said:

"One of the things I picked up from him was to give someone a task and have confidence in them, give them the space in which to do it, not to keep jumping down their throats every five minutes. And have people feel that if something goes wrong, they could go and say, l've done this wrong, and you'll say, right, we'll work through it, not blow your top. I can see how that works."

\section{DISCUSSION}

These findings provide more evidence that ambitious young women tend to use a selection of role models in order to guide them through their careers and build appropriate identities. They were not falling into the trap 
identified by Shapiro et al. (1978) of searching for a single perfectly matched female role model. Six of them had males in their set too. None of the women had a single or total role model, but they did not seem to have an idealised "composite" role model either, in the way suggested by Bucher and Stelling (1977). It was more a sense of drawing on different role models for different strengths, but not necessarily building them together again into a reconstructed ideal self. However, the metaphor of unfreezing, changing and refreezing suggested by Ashforth (1998) was relevant for the young women who reported that they were at a cross-roads and reconciling their life plans and career plans, after drifting along in their own comfort zones.

"It was very useful mapping out
the role models like this, because
it made me think, why does it look
like this. Why is my mother not
there? She has her own career,
she is an artist. She is very strong
in that, and I can't see why I
wouldn't look at her as a role
model in terms of my career - I
don't draw on her at all. When I
think about the shortcomings of
this map, I think it is because I am
at this crossroads. Maybe I'm too
focused on personalities, and not
enough on goals and my career,
which I think is quite a key thing
just now."

But other women still often used their parents as reference points when uncertain what to do, considering what their parent would have done in similar circumstances.

Thus, the set of partial role models emerged as the most common structure. However, as interviewees had been asked to map out their role model set graphically, this may have influenced the way in which they reported their use of role models to the researcher.

Just as Lockwood and Kunda (1997) reported, some 'superstars' were selected by these young women. This was unexpected. Perhaps so much is written about some of these females that young women actually know much more "information" about them from TV, magazines and newspapers, whether true or not, compared to their knowledge of the women business leaders, other than a few stars at the top who were written about in the financial pages. Role modelling is assumed to include social learning (Bandura, 1977) involving observing and emulating behaviours, styles and attributes of role models. Whilst the choice of celebrity role models might occur because they are frequently in the public gaze, offering glimpses of their behaviour, an alternative view can be offered which might extend the Higgins and Kram (2001) framework used in this paper. The Higgins and Kram framework was adopted from mentoring that, by definition, involves personal contact and offers opportunities for social learning. However, the notion of close and distant role models, implicit in discussion of role modelling, may be a useful distinction to make and for which different psychological learning processes may be engaged.

Near and distant has been a concept explored in the leadership literature, for example, Shamir (1995). In that context, near and far leaders are ascribed different characteristics; distant leaders are characterised by notions of having ideological missions, by courage, persistence in the face of difficulty, determination. Near leaders who are observable and known personally are more likely to be characterised in terms of openness, sociability and humour. The idea of charisma and other hard to copy characteristics are more typical of the' ideal self' or aspects of self that are difficult to identify with and access. These are more often ascribed to distant leaders than near leaders.

This may also be the case for role models and further studies could do well to explore near and distant aspects of role modelling. At a crossroads in a career when new steps need to be taken, a person must find within their potential, aspects of themselves hitherto untapped. Often these aspects of self have been unconscious, perhaps even unwanted in the individual's life so far. For women, these often correspond to characteristics associated with leaders but not necessarily with femininity. A positive identification with these aspects of one's self is necessary to have the confidence to take the next step. For example, standing one's ground and having a high profile on a contentious issue is more probable if one's identity includes being courageous and persistent. Yet women are often socialised into harmonious and yielding behaviours. Thus the assertive aspect is present but unconscious and unformed.

A distant role model is the ideal way of accessing these potentials. The process of splitting and projection is involved (derived from Object Relations theory, see for example Klein's 1959 seminal paper). In this process, 
aspects of oneself that are unconscious or difficult to own are projected, as if like a cinematic projector, onto suitable others. The person onto whom the projection is made is then seen to possess these difficult aspects (which may be viewed by other people as very positive characteristics) and the projector does not have to deal with them as part of their own personality. However, successfully reintegrating these projections enables the person to consciously own and identify them as part of their personality. A celebrity who has some superficial similarity to the aspects of self that are required in a future role is an ideal projective screen. Although a person may imagine knowing a lot about a celebrity, in reality anything can be projected onto their persona. So Madonna may be seen as courageous and stands her ground, yet we know little of how she actually does or does not do this in her personal life. The idea of Madonna can be used to incorporate courageous attributes that lie dormant in the person who sees her as a role model into a new set of desired behaviours. In identifying with her as a role model, the young woman can integrate courage and assertiveness into her own identity and own them as positive aspects of herself because the celebrity is lauded and has the approval of a significant part of society. This may be particularly important for those characteristics, for example, increasing independence of opinion, or taking conflict head on, which women might fear could meet with disapproval in their own case.

Hence, the use of distant role models may have less to do with social learning and more to do with individuation and psychological growth. Gibson (2003) found stage one career involved near role models, whilst in later stages, the issues were to do with role models affirming the user's self-concept. Superstars and celebrities are ideal for this, and mentoring and coaching could incorporate an understanding of this process to support mentees and coachees in re-integrating and owning these projections. Exploring who the distant role models are for the individual, and why, would be a helpful part of this work.

Work-life balance came up in only two interviews, but the issue of combining career and future motherhood was mentioned by six women. Perhaps the former finding was because balance at present was not difficult to attain, as none of the women had children. A strong need emerged from four of the women for expression of their more artistic sides, which was being suppressed in busy jobs. These included painting, literature, theatre, dance and music, and again may help explain why role models were sought from such domains. The notion of what is being suppressed and the choice of role model to access the suppressed side of one's self supports the idea that distant role models may assist through their potential use as a projective screen.

There is an important issue concerning the few businesswomen identified as role models, if this is a general issue for women in this age group in early professional careers. The consequences of lack of business role models are serious for women, who do not see career possibilities as clearly as they would wish. They may scale down their ambition, their potential is under-developed, and often they stagnate or leave to find rewards elsewhere. There is also a problem for organisations without female role models, as indicated by Sheppard (1989). Their female managers have to spend additional time and effort ascertaining how to behave and present themselves at work, with little support available at senior levels from colleagues or peers who are similar by gender. Sexualisation and objectivisation of women at work are often used as instruments of power by male colleagues, as a way of controlling competition for scarce promotions. There are particular problems associated with women going on maternity leave and returning to positions of responsibility, where few or even no women have successfully operated after becoming mothers. There is often inappropriate behaviour from males, both individually and as groups, because they are not used to dealing with managerial women. Without female role models, women turn to desexualisation of themselves at work as a coping strategy. They constrain their feminine side in case it is seen as stereotypically unprofessional or as attractive and hence inviting of male sexual attention. Leadership and management styles therefore continue to be masculine as the feminine is not expressed and is undervalued by both males and females (Schein and Mueller, 1992).

\section{CONCLUSIONS}

This small, exploratory study brings empirical evidence of the role modelling process as experienced by young female professionals, in a field that has been somewhat neglected for nearly a decade, apart from Gibson (2003; 2004). Building also on earlier work by Shapiro et al.(1978) and Bucher and Stelling (1977), 
the paper contributes an understanding of how women seeking business career advancement use role models in a variety of domains for different purposes to guide their own development, rather than seeking a single ideal type match with themselves. In addition, the paper indicates that women draw on more role models from the business world, but do not include many very senior business women. Most of the sample had multiple role models, and preferred close or near role models to those more distant and not personally known to the user.

We acknowledge the limitations of this research in terms of the small sample, whose career awareness had been raised by the recent career seminar. Further research is suggested using a larger sample, across genders to see how much commonality there is between young professionals. It would also be useful to study the way in which role models are used at the threshold of senior management, usually the glass ceiling in most organisations. It is anticipated that a much more business-focused approach would be used to identify the role models, and that the learning at this more senior levels would be more focused on developing appropriate leadership behaviours. Given that so many women managers quote the lack of appropriate role models as a key barrier to advancement, it is surely time for research studies to measure the contributions made by role models.

\section{REFERENCES}

Ashforth, B. (1998) "Becoming: How does the process of identification unfold?". In D.A. Whetten and P. C. Godfrey (eds.) Identity in Organisations: Building Theory through Conversations, Sage, Thousand Oaks, 213222.

Bailyn, L., Drago, R. and Kochan, T. (2001) Integrating Work and Family Life: A Holistic Approach, Alfred P. Sloane Foundation Work-Family Policy Network, MIT.

Bandura, A. (1977) Social Learning Theory, Prentice Hall, Eaglewood Cliffs, NJ.

Bucher, R. and Stelling, J. (1977) Becoming Professional, Sage, Beverley Hills CA.

Catalyst (2000) The MBA Report, Catalyst, New York.

Catalyst/Conference Board (2003) Women in Leadership: Comparing European and US Women Executives, Catalyst/Conference Board Report, Catalyst, New York.
Chung, K.-S. (2000) "Role models and arguments for affirmative action", American Economic Review, 90 (3) 640-648).

Ely, R.J. (1994) "The effects of organisational demographics and social identity on relationships among professional women", Administrative Science Quarterly, 39, 203238.

Gibson, D.E. (2003) "Developing the professional self-concept: Role model construals in early, middle and late career stages", Organization Science, 14 (5) 591610.

Gibson, D.E. (2004) "Role models in career development: New directions for theory and research", Journal of Vocational Behavior, 65, 134-156.

Higgins, M.C. and Kram, K.E. (2001) "Reconceptualizing mentoring at work: A developmental network perspective", Academy of Management Review, 26 (2) 264-288.

Hill, L. (1992) Becoming a Manager: Mastery of a New Identity, Harvard Business School Press, Boston.

Ibarra, H. (1999) "Provisional selves: Experimenting with image and identity in professional adaptation", Administrative Science Quarterly, 44, 764:791.

Ibarra, H. (2000) "Making partner: A mentor's guide to the psychological journey", Harvard Business Review, 78 (2) 147-155.

Javidan, M., Bemmels, B., Devine, K.S., Dastmalchian, A. (1995), Superior and Subordinate Gender and the Acceptance of Superiors as Role Models. Human Relations; . 48, 11, 1271-1284

Klein, M (1959) 'Our adult world and its roots in infancy' Human Relations Vol.12 pp 291-303 Lockwood, P., Jordan, C. and Kunda, Z. (2002) "Motivation by Positive or Negative Role Models: Regulatory focus determines who will best inspire us", Journal of Personality and Social Psychology, 83 (4) 854-864.

Lockwood, P. and Kunda, Z. (1997) "Superstars and me: Predicting the impact of role models on the self", Journal of Personality and Social Psychology, 73 (1) 91-103.

Lofland, J. and Lofland, L.H. (1995) Analysing Social Settings, Wadsworth, Belmont, CA.

Louis, M. R. (1980) "Surprise and sensemaking: What newcomers experience in entering unfamiliar organisational settings", Administrative Science Quarterly, $25,226-251$

Scarnati, J. (2002) "Leaders as role models: 12 Rules", Career Development International, 7 (3) 181-189. 
Schein, E. H. (1968) "Organisational socialisation and the profession of management", Sloan Management Review, 9 (2) 1-16.

Schein, V. and Mueller, R. (1992) "Sex role stereotyping and requisite management characteristics: A cross-cultural look", Journal of Organisational Behavior, 13, 439447.

Shamir, B (1995) "Social distance and charismatic leadership; Theoretical notes and an exploratory study", Leadership Quarterly Vol. 6 No 1 pp 19-47

Shapiro, E.C., Haseltine, F. P. and Rowe, M. P. (1978), Moving up: Role models, mentors, and the "patron system. Sloan Management Review; 19, 51-58.
Sheppard, D.L. (1989) "Organisations, Power and Sexuality: The Image and Self-Image of Women Managers", in Hearn, J., Sheppard, D.L., Tancred-Sheriff, P. \& Burrell, G. (editors), The Sexuality of Organisation, Sage, London.

Sinclair, S. (1997) Making doctors: An institutional apprenticeship, Berg, Oxford.

Singh, V. \& Vinnicombe, S. (2004) The 2004 Female FTSE Report 2004,. Cranfield School of Management Report, Cranfield, December.

Vinnicombe, S., Singh, V. \& Sturges, J. (2000) "Making it to the Top in Britain", chapter in R.Burke \& M Mattis (Eds) Women on Corporate Boards of Directors: International Challenges and Opportunities, Kluwer Academic Press, Dordrecht, Netherlands 